\title{
Genetic variations in the PSMA6 and PSMC6 proteasome genes are associated with multiple sclerosis and response to interferon- $\beta$ therapy in Latvians
}

\author{
NATALIA PARAMONOVA ${ }^{1}$, JOLANTA KALNINA ${ }^{1}$, KRISTINE DOKANE ${ }^{1}$, KRISTINE DISLERE $^{1}$, \\ ILVA TRAPINA $^{1}$, TATJANA SJAKSTE ${ }^{1}$ and NIKOLAJS SJAKSTE ${ }^{1,2}$ \\ ${ }^{1}$ Genomics and Bioinformatics, Institute of Biology of The University of Latvia; \\ ${ }^{2}$ Department of Medical Biochemistry of The University of Latvia, LV-1004 Riga, Latvia
}

Received July 8, 2020; Accepted December 8, 2020

DOI: $10.3892 /$ etm.2021.9909

\begin{abstract}
Several polymorphisms in genes related to the ubiquitin-proteasome system exhibit an association with pathogenesis and prognosis of various human autoimmune diseases. Our previous study reported the association between multiple sclerosis (MS) and the PSMA3-rs2348071 polymorphism in the Latvian population. The current study aimed to evaluate the PSMA6 and PSMC6 genetic variations, their interaction between each other and with the rs2348071, on the susceptibility to MS risk and response to therapy in the Latvian population. PSMA6-rs2277460, -rs1048990 and PSMC6-rs2295826, -rs2295827 were genotyped in the MS case/control study and analysed in terms of genotype-protein correlation network. The possible association with the disease and alleles, single- and multi-locus genotypes and haplotypes of the studied loci was assessed. Response to therapy was evaluated in terms of 'no evidence of disease activity'. To the best of our knowledge, the present study was the first to report that single- and multi-loci variations in the PSMA6, PSMC6 and PSMA3 proteasome genes may have contributed to the risk of MS in the Latvian population. The results of the current study suggested a potential for the PSMA6-rs1048990 to be an independent marker for the prognosis of interferon- $\beta$ therapy response. The genotype-phenotype network presented in the current study provided a new insight into the pathogenesis of MS and perspectives for future pharmaceutical interventions.
\end{abstract}

Correspondence to: Dr Ilva Trapina, Genomics and Bioinformatics, Institute of Biology of The University of Latvia, Jelgavas Street 1, LV-1004 Riga, Latvia

E-mail: ilva.trapina@lu.lv

Key words: multiple sclerosis, PSMC6-PSMA6-PSMA3, rs1048990, molecular biomarkers; single nucleotide polymorphisms, no evidence of disease activity, proteasome, therapy interferon- $\beta$

\section{Introduction}

Multiple sclerosis (MS) is a lifelong demyelinating disease of the central nervous system. The clinical onset of MS tends to be between the second and fourth decade of life. Similarly to other autoimmune diseases, women are affected 3-4 times more frequently than men (1). About $10 \%$ of MS patients experience a primary progressive MS form characterized by the progression of neurological disability from the onset. In about $90 \%$ of MS patients, the disease undergoes the relapse-remitting MS course (RRMS); in most of these patients, the condition acquires secondary progressive course (SPMS) (2).

The cause of MS is not clear. It is widely believed to be an autoimmune disorder triggered in genetically predisposed subjects by environmental factors such as infection, exposure to sunlight, and vitamin D deficiency (3-5). The vitamin deficiency and other genetic factors may also contribute to the augmented production of proinflammatory cytokines such as IL-12, IL-18 and macrophage migration inhibitory factor that have been found during the active phases of the disease (6-9). Recent evidence indicated that these abnormal production of proinflammatory cytokines may reside in the hyperactivation of the inflammasome (10). Simultaneously, MS patients showed reduced production of anti-inflammatory cytokines such as IL-37 as well as endogenous anti-inflammatory mediators such as IL-1 receptor antagonist, the soluble IL-1 receptor type 2 and heme oxygenase I (11-14). MS susceptible loci have been identified in regions containing genes with immune, co-stimulatory, signal transduction functions and related to vitamin D function (15-21).

Ubiquitin proteasome system (UPS) plays a vital role in immunity and its deregulation and/or modulation may influence MS development and progression. The $20 \mathrm{~S}$ proteasome has been identified as a target of the humoral autoreactive immune response (22) and a major autoantigen in MS patients (23). Proteolytic activities of proteasomes are reduced in the brain tissue of MS patients (24). Inhibition of proteasomes and lysosomal proteases involved in major histocompatibility complex (MHC) II antigen presentation has shown to improve MS therapeutic efficacy $(22,25)$. Disease-modifying treatments significantly decrease the 
frequency of relapses and impede the progression of disability during MS (26). Interferon- $\beta$-1b (IFN $\beta$-1b) reduces relapses in MS and improves magnetic resonance imaging (MRI) outcomes. Plasma levels of ubiquitin and proteasome enzymatic activity in MS patients before IFN $\beta$-1b therapy have been shown to decrease after six months of treatment (25). In a similar manner, treatment with IFN $\beta$ augments other endogenous anti-inflammatory mediators such as TGF $\beta$, Heme oxygenase 1 and IL-1 receptor antagonist thus pointing out to its pleiotropic pharmacological effects $(12,14,27)$. Preliminary studies have shown that the potency of IFN $\beta$ can be increased further by simultaneous treatment with cyclophosphamide in patients with aggressive diseases (28). In this case, studies to identify pathways genes that predict a successful response to this treatment combination appear promising. Similarly, on the basis of analysis of genes and biomarkers it was possible to predict therapeutic effects of natalizumab (6,29-31).

Genetic variations in PSMA3 and PSMB9 proteasome genes were reported to be associated with the risk of MS in Latvians (32) and Italians (33). Polymorphisms of the 14q11-24 proteasome genes PSMA6 and PSMC6 were previously involved in susceptibility to juvenile idiopathic arthritis (JIA) (34), asthma in children (BA) (35) and obesity (OB) (36), type 2 and type 1 diabetes mellitus (T1DM and T2DM) (37-39), cardiovascular disorders $(39,40)$ and adaptation to the environment of the population (41). Taking into account that the statistically proven phenomena of the coexistence of autoimmune diseases (42) might happen that some of these polymorphisms are associated with susceptibility to MS, disease prognosis and/or response to therapy.

The aim of the current study was to evaluate the association of genetic variations in the proteasome genes PSMA6 (rs2277460 and rs1048990) and PSMC6 (rs2295826 and rs2295827) encoding regulatory $\alpha$-subunit and ATPase subunit respectively with MS development and response to the therapy in Latvians. Additionally, the interaction of the PSMA6 and PSMC6 polymorphisms with the rs2348071 locus in the PSMA3 genes were analysed on MS susceptibility. Further on, using publicly available SNPexp database (43) on correlations between SNP genotype and gene expression levels in lymphoblastoid cells of individuals included in the HapMap populations, we performed an in silico analysis of the association between the SNPs analysed and the expression levels of the number of previously reported MS gene candidates and genes involved in the interferon signalling pathway. Genotype-phenotype correlations identified in the study may provide a new insight on MS pathogenesis and response to the therapy.

\section{Materials and methods}

Case-control study. The case group consisted of $280 \mathrm{MS}$ patients (mean age: $41.66 \pm 12.16$ years) attending the Latvian Maritime Medicine Centre, Vecmilgravis Hospital. MS patients were diagnosed according to the revised 2010 McDonald criteria (44) and assigned to RRMS (187 patients; mean age: $38.88 \pm 12.81$ years) and SPMS (93 patients; mean age: $51.20 \pm 9.94$ years) groups. The control group of 305 individuals representing the total Latvian population was previously described $(32,38)$. All controls were carefully assessed to exclude the diagnosis of any inflammatory disorders. Written consent was obtained from all participants of the study. The study was performed according to the Declaration of Helsinki and the study protocol was approved by the Central Medical Ethics Committee of Latvia (Protocol Nr. 01-29.1/17).

Treatment. Three disease-modifying agents, including IFN $\beta$, glatiramer acetate and mitoxantrone, were used for the treatment of 210 MS patients. Details on therapy are given in Table I.

Response to therapy evaluation. Progress of disease and response to treatment were evaluated in terms of "no evidence of disease activity' (NEDA) standard (45) measured by relapses, the progression of disability and new and/or enlarging demyelinating lesions as seen on MRI.

DNA extraction and genotyping. Genomic DNA extraction and the rs2277460, rs1048990, rs2295826 and rs2295827 genotyping technologies (primer sequences, necessary Polymerase Chain Reaction procedure and analysis of amplified and digested products) were the same as in $(34,41)$. For quality control, 16 randomly chosen samples per each marker were genotyped in two different experiments. Genotyping data were verified by direct sequencing of the corresponding DNA fragments in both directions using Applied Biosystems 3130xl Genetic Analyzer (Fig. S1). Loci description and nucleotide numbering are given according to the recommended nomenclature system (http://www.genomic.unimelb.edu. $\mathrm{au} / \mathrm{mdi} / \mathrm{mutnomen} / \mathrm{recs} . \mathrm{html}$ ). Chromosome 14, GRCh37.p5 assembly (NCBI reference sequence: NC_000014.8) sequence information was used for loci description.

Data analysis. Single locus genotypes' and alleles' frequencies were estimated in the MS group by direct gene counting. The genetic diversity of SNPs rs2277460, rs1048990, rs2295826 and rs2295827 was studied previously by Sjakste et al, 2016 (38) in the control group. Genotyping data on the rs2348071 variations in MS patients were described by Kalnina et al, 2014 (32). These primary genotyping data were used in the current case/control study to construct multi-locus genotypes, haplotypes and identify the main effects of MS in single- and multi-locus models. Deviation from the Hardy-Weinberg equilibrium (HWE) and the differences between case and control groups in allele, genotype and haplotype frequencies were evaluated by $\chi^{2}$ using XLSTAT software for Windows (Data Analysis and Statistical Solution for Microsoft Excel, https://www.xlstat.com/en, Addinsoft, Paris, France 2017). Dominant, recessive, over dominant and multiplicative genetic models for every individual locus were designed according to (46), and two- or one-tailed P-value (significant $<0.05$ ) was evaluated by $\chi^{2}$ using $2 \times 2$ contingency tables. Odds ratio (OR) higher than two (2) and lower than 0.5 was considered to be clinically significant (46). Stratification was performed by MS course, NEDA standard and response to the therapy.

Genotype-phenotype correlation analysis. Data on the correlation between SNPs' genotypes and expression levels of the number of genes potentially involved in MS pathogenesis (15-20) and/or response to the IFN $\beta$ therapy (PathCards, https://pathcards.genecards.org/card/immune_ response_ifn_alphabeta_signaling_pathway) were derived 
Table I. Multiple sclerosis treatment and response to therapy.

Patient number

\begin{tabular}{|c|c|c|c|c|c|c|}
\hline $\begin{array}{l}\text { Disease-modifying } \\
\text { agent }\end{array}$ & $\begin{array}{l}\text { Commercial } \\
\text { name }\end{array}$ & Manufacturer & Formulation of treatment & $\begin{array}{l}\text { Total } \\
\text { treated }\end{array}$ & Respon-ders & Non-responders \\
\hline IFN $\beta$ total & & & & 148 & 37 & 111 \\
\hline$I F N \beta-1 a$ & Avonex $^{\circledR}$ & Biogen Idec Limited & $\begin{array}{l}\text { Intramuscular } 30 \mu \mathrm{g} \text { once } \\
\text { weekly }\end{array}$ & 25 & 10 & 15 \\
\hline$I F N \beta-1 a$ & Rebif $^{\circledR}$ & $\begin{array}{l}\text { Merck Serono; } \\
\text { Merck KGaA }\end{array}$ & $\begin{array}{l}\text { Subcutaneous } 44 \mu \mathrm{g} \text { three } \\
\text { times per week }\end{array}$ & 59 & 14 & 45 \\
\hline$I F N \beta-1 b$ & $\begin{array}{l}\text { Betaseron }^{\circledR} \\
\text { or Extavia }^{\circledR}\end{array}$ & Bayer AG & $\begin{array}{l}\text { Subcutaneous } 250 \mu \text { g every } \\
\text { other day }\end{array}$ & 64 & 13 & 51 \\
\hline Glatiramer acetate & Copaxone $^{\circledR}$ & $\begin{array}{l}\text { TEVA Pharmaceutical } \\
\text { Industries, Ltd }\end{array}$ & $\begin{array}{l}\text { Subcutaneous } 20 \mathrm{mg} \text { once } \\
\text { a day }\end{array}$ & 39 & 4 & 35 \\
\hline Mitoxan-trone & Novantrone $^{\circledR}$ & Wyeth Laboratories & $\begin{array}{l}\text { Intravenous once every } \\
3 \text { months }\end{array}$ & 23 & 0 & 23 \\
\hline
\end{tabular}

Therapeutic forms of IFN $\beta$ can be produced in bacterial expression systems (IFN $\beta$-1b) or in mammalian cells (IFN $\beta$ - $1 \mathrm{a})$. IFN $\beta$, interferon $\beta$.

using SNPexp online tool [http://tinyurl.com/snpexp., Norwegian PSC Research Center, Rikshospitalet, Oslo, Norway (43)] for lymphoblastoid cells of all unrelated individuals of the HapMap phase II release 23 data set which consist of 3.96 million SNP genotypes from 270 individuals from four populations: CEU (90 Utah residents with ancestry from northern and western Europe), HCB (45 unrelated Han Chinese in Beijing), JPT (45 unrelated Japanese in Tokyo), YRI (90 Yoruba in Ibadan, Nigeria). Dominant and additive genetic models were tested for correlation analysis. The Spearman' correlation between genotype and the gene expression level was considered to be positive if at least one probe per transcript showed a statistically significant association $(\mathrm{P}<0.05)$.

Taking into account that in the SNPexp platform (43) one gene can be represented by several probes, but one probe maps only one gene, the results were manually filtered: 1) To exclude possible false calls when one probe is found to belong to several genes; 2) to optimize repeated data when several probes map to one gene; 3 ) to exclude potentially false calls identified for the rs2295826, but not for the rs2295827.Only Spearman correlations with P-value less than 0.05 or significant correlation found for both the rs2295826 and rs2295827 were taken into account. The data obtained as a result of filtration is given in Tables SI and SII.

\section{Results}

Genotyping results and single-locus association analysis. In the current study, we have genotyped the rs2277460, rs1048990, rs2295826 and rs2295827 in 280 MS patients. In Latvia there are 2035 registered MS patients in total. The study can be considered to be a representative for the Latvian population, as $13.7 \%$ of all patients were covered by our study. Since significance was achieved and revealed the trend on the association with the disease, our results appeared to predict the common association trends for larger sample groups, with the possibility of further studies reproduced in other populations.
Data on alleles' and genotypes' distributions and single-locus associations are given in Table II. The Genotyping call rate was $100 \%$ and all genotyped markers were found to be in a perfect HWE $(\mathrm{P}>0.05)$. The rs2295826 and rs2295827 were observed in a complete $\left(D^{\prime}=1, r^{2}=1\right)$ linkage disequilibrium and in further analysis, the linkage block rs2295826-rs2295827 will be represented by the rs2295826 locus. No linkage had been identified between other polymorphic loci analysed $(\mathrm{P}>0.05)$.

The rs2277460 and rs1048990 exhibited similar alleles' and genotypes' frequencies in the cases and controls and appeared to be MS neutral.

The linkage block rs2295826-rs2295827 showed statistically significant MS main effect for both rare alleles $[\mathrm{P}<0.05$; odds ratio, $\mathrm{OR}=1.62,95 \%$ confidence interval $(\mathrm{CI})(1.16-2.26)]$ and genotypes in the dominant model $[\mathrm{P}<0.001 ; \mathrm{OR}=1.95$, 95\% CI (1.34-2.83)].

Identification of the risk/protective multi-loci genotypes. Using personalized data documentation, we reconstructed individual multi-loci genotypes and tested them on the association with the disease. Full-spectrum and frequencies of the rs 22774 60-rs1048990-rs2295826-rs2295827-rs2348071 genotypes is presented in Table SIII. Genotype having the homozygotes on major alleles simultaneously at the rs2277460 and rs1048990 and MS risk genotypes at the rs2295826-rs2295827 and rs2348071 showed a strong association with the disease [4-LG7, P=0.0001; OR=3.01, 95\% CI (1.70-5.33)]. Genotypes including risk alleles at loci rs2277460, rs2295826-rs2295827 and rs2348071 (4-LG12) and risk genotypes at loci rs2277460 and rs2295826-rs2295827 (4-LG11) were found about two times more frequently in MS patients than in controls.

Genotype homozygous on major alleles at all five loci was the most frequent in controls (28\%) and second by frequency in MS patients $(\sim 18 \%)$ showing significant disease protective effect $[\mathrm{P}<0.05 ; \mathrm{OR}=0.31,95 \%$ CI $(0.66-0.96)$, Fig. $1 \mathrm{~A}$, Table SIII]. 
Table II. SNP genotype and MA frequencies and data on association with MS.

\begin{tabular}{|c|c|c|c|c|c|}
\hline \multirow[b]{2}{*}{ SNP ID and MA or genotype } & \multirow[b]{2}{*}{ MS $(n=280)$} & \multirow[b]{2}{*}{ Controls $(\mathrm{n}=305)$} & \multicolumn{3}{|c|}{ Data on association } \\
\hline & & & Genetic model & P-value & OR $[95 \% \mathrm{CI}]$ \\
\hline \multicolumn{6}{|l|}{$r s 2277460$} \\
\hline A & $51(9.11)$ & $44(7.21)$ & A vs. C & $\mathrm{n} / \mathrm{s}$ & - \\
\hline $\mathrm{CC}$ & $229(81.79)$ & $261(85.57)$ & - & - & - \\
\hline $\mathrm{CA}$ & $51(18.21)$ & $44(14.43)$ & CA vs. CC & $\mathrm{n} / \mathrm{s}$ & - \\
\hline \multicolumn{6}{|l|}{ rs1048990 } \\
\hline $\mathrm{G}$ & $50(8.93)$ & $57(9.34)$ & G vs. C & $\mathrm{n} / \mathrm{s}$ & - \\
\hline $\mathrm{CC}$ & $233(83.21)$ & $250(81.97)$ & - & - & - \\
\hline $\mathrm{CG}$ & $44(15.72)$ & $53(17.38)$ & $\mathrm{CG}+\mathrm{GG}$ vs. $\mathrm{CC}$ & $\mathrm{n} / \mathrm{s}$ & - \\
\hline GG & $3(1.07)$ & $2(0.65)$ & - & - & - \\
\hline \multicolumn{6}{|l|}{$r s 2295826$} \\
\hline $\mathrm{G}$ & $96(17.14)$ & $69(11.31)$ & G vs. A & 0.0042 & $1.62[1.16-2.26]$ \\
\hline AA & $187(66.79)$ & $243(79.67)$ & - & - & - \\
\hline AG & $90(32.14)$ & $55(18.03)$ & $\mathrm{AG}+\mathrm{GG}$ vs. $\mathrm{AA}$ & 0.0004 & $1.95[1.34-2.83]$ \\
\hline GG & $3(1.07)$ & $7(2.30)$ & - & - & - \\
\hline \multicolumn{6}{|l|}{$r s 2295827$} \\
\hline $\mathrm{T}$ & $96(17.14)$ & $69(11.31)$ & $\mathrm{T}$ vs $\mathrm{C}$ & 0.0042 & $1.62[1.16-2.26]$ \\
\hline $\mathrm{CC}$ & 187 (66.79) & $243(79.67)$ & - & - & - \\
\hline $\mathrm{CT}$ & $90(32.14)$ & $55(18.03)$ & $\mathrm{CT}+\mathrm{TT}$ vs. $\mathrm{CC}$ & 0.0004 & $1.95[1.34-2.83]$ \\
\hline $\mathrm{TT}$ & $3(1.07)$ & $7(2.30)$ & - & - & - \\
\hline
\end{tabular}

Numbers of alleles and genotypes (in brackets, frequency in percent) in control are given according to (38). MS and Control data are presented as $\mathrm{n}(\%)$. MA, minor allele; MS, multiple sclerosis; OR [95\% CI], odds ratio with 95\% confidential interval, indicated when $\mathrm{n} / \mathrm{s}$ (no statistical result or $\mathrm{P}>0.05$ ); SNP, single nucleotide polymorphism.

Further on, we analysed the interaction between any two loci (the rs2295826-rs2295827 linkage block was considered as one locus) on MS susceptibility. Data on statistically significant interactions are illustrated in Fig. 2.

The rs2295826-rs2348071 Risk-Risk genotype, was more than twice more frequent in MS patients $(22.14 \%)$ than in controls $(8.54 \%)$ and showed strong $(\mathrm{P}<0.0001)$ association with the disease [OR=3.60, 95\% CI (1.60-4.22); Fig. 2A]. The rs2277460-rs2295826 genotype of the CA-Risk structure rarely observed in controls (2.63\%) was more frequent in MS patients $(6.43 \%)$ showing nominal $(\mathrm{P}<0.05)$ association with the disease [OR=2.45, 95\% CI (1.05-5.73); Fig. 2B].

Haplotype analysis. Results on haplotype analysis are given in the Table SIV and illustrated in Fig. 1B.

Haplotype diversity was similar in both groups of MS patients and healthy individuals. Although, the rs 2277460 locus did not show MS susceptibility in a single-locus analysis, the haplotype of the A-C-A-C-G structure (Hap6) showed a significant association with the disease $[\mathrm{P}<0.001 ; \mathrm{OR}=2.44$ 95\% CI (1.45-4.11), Fig. 1B].

The rs2277460-rs1048990-rs2295826-rs229582 7-rs2348071 haplotype of the C-C-G-T-A composition (Hap8) having MS risk alleles at the rs2295826-rs2295827 and rs2348071 loci simultaneously, showed strong $(\mathrm{P}<0.0001)$ association with the disease [OR=9.65 95\% CI (4.49-20.76),
Fig. 1B] supporting the above presented data on the single- and multi-loci genotype susceptibility.

Polymorphism association with the response to therapy. Patients did not respond to mitoxantrone therapy. Among 39 patients treated by glatiramer acetate, only four were susceptible to this treatment. In the group of 148 patients treated with IFN $\beta, 37$ responders were detected (Table I).

Genotyping data were further analysed for the association with response to IFN $\beta$ therapy (Table III). Alleles' and genotypes' distribution were found to be similar between responders and non-responders at the rs2277460, rs2295826-rs2295827 and rs2348071. However, the $\mathrm{G}$ allele at the rs1048990 was approximately twice more frequent in non-responders than in responders and the association of the $G$ allele with no IFN $\beta$ therapy response was found to be close to statistical significance [Table III; OR=2.53 95\% CI $(0.907 .08)$ in the multiplicative model].

Correlation between SNPs' genotype and gene expression. Suggesting the potential for genetic variations to produce a local or distant functional effect in the genome, we analysed the further correlation between genotypes of the rs1048990, rs2295826-rs2295827 and rs2348071, identified in the current and previous (32) studies as MS susceptible and expression levels of 13 well-characterized genes associated with the 

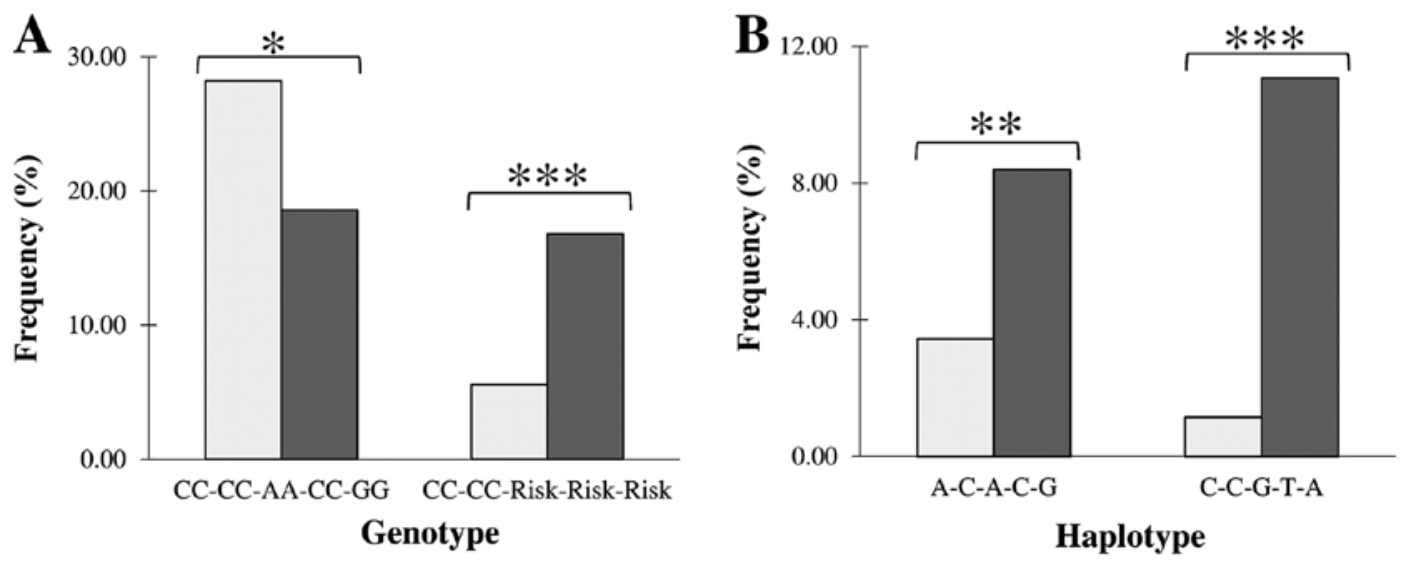

Figure 1. Presentation of the controls and patients with multiple sclerosis of the (A) 5 loci genotypes and (B) 5 loci haplotypes associated with the disease in the Latvian population. Light and dark columns correspond to controls and cases, respectively. ${ }^{*} \mathrm{P}<0.05,{ }^{* *} \mathrm{P}<0.001$ and ${ }^{* * *} \mathrm{P}<0.0001$ correspond to nominal, moderate and strong levels of statistical significance calculated by $\chi^{2}$ or Fisher's exact test.

susceptibility to MS (15-20) and 21 genes involved in IFN $\alpha / \beta$ signalling pathway (PathCards, https://pathcards.genecards. org/card/immune_response_ifn_alphabeta_signaling_pathway). The name of the $C D 25$ gene was not found on the expression chips. A statistically significant correlation between mRNA transcript level and genotypes of any SNP was found for six genes implicated in MS pathogenesis and nine genes involved in IFN pathways (Tables IV and SII).

Examples of correlations revealed and details on the correlated genes are given in Fig. 3 and Table SII, respectively. Risk genotypes of the rs1048990 and rs2348071 were found in a simultaneous correlation with expression levels of the IL7R (Fig. 3B), STAT3 (Fig. 3C), TNFRSF5 (Fig. 3D), $P T P-1 B$ (Fig. 3E) and USPI8 (Fig. 3F). Fig. 3A illustrated the situation when the $H L A-B$ expression level correlates with the rs2295826 and rs2295827.

\section{Discussion}

The main finding of this study is that the PSMC6-rs2295826-rs2295827 and PSMA3-rs2348071 loci showed MS susceptibility, and data on single-locus associations were confirmed by haplotype and multi-loci genotype analysis. Remarkably, MS susceptible to rs2277460-rs1048990-rs2295826 -rs2348071 haplotypes of the A-C-A-C-G and C-C-G-T-A configuration is identified in this study (Fig. 1B) were found to be linked with poly-JIA and oligo-JIA, respectively (41), and T1DM (38). Similarly, multi-loci genotype CC-CC-Risk-Risk-Risk, associated with MS risk effect in this study (Fig. 1A), is also a risk factor for T1DM (38), BA (35) and JIA (41). We did not find any data about the association of the polymorphisms studied by us with MS in the literature. However, haplotypes encompassing the KIAA0391 localized in 14q13.2 and PSMA6 gene cluster confer a genetic link for myocardial infarction and coronary artery disease (47). Additionally, in a GWAS study performed by the International Multiple Sclerosis Consortium (48) on association of SNP rs12436216 of the gene KIAA0391, it was reported that 14q13.2 could be a MS susceptibility locus.

Some loci of susceptibility may be shared among many autoimmune and other immune-mediated diseases $(49,50)$. Earlier, the pleiotropic genetic effect as a frequent phenomenon in human complex traits and diseases (51) has been reported for BA and OB $(52,53)$ and for BA and juvenile rheumatoid arthritis $(54,55)$. Similarly, rs2277460 associated with BA in our previous study (35) has been found to determine susceptibility in Latvians with JIA (34) and T1DM (38). This locus turned out not to be associated with MS primary cohort in a single-locus analysis in Latvians, however, it was found in the block of interaction of risk loci PSMA6-rs2277460-PSM C6-rs2295826, which was more frequent in disease's group (Fig. 2B). This data was confirmed by haplotype analysis: Haplotype A-C-A-C-G included only the rs2277460 risk allele $\mathrm{A}$ and showed a significant association with $\mathrm{MS}[\mathrm{P}<0.001$; $\mathrm{OR}=2.4495 \% \mathrm{CI}$ (1.45-4.11), Fig. 1B].

In silico analysis revealed $(34,41)$ that the nucleotide substitutions we have studied, modified transcription factor (TFs) binding sites and miRNAs. This can significantly modulate the transcription of related genes and gene networks in response to the inflammation and other environmental stimuli.

The PSMA6-rs2277460 and PSMA3-rs2348071 rare alleles and the PSMC6-rs2295826 major allele assisted the cytoplasmic ribonucleoprotein hnRNPA1 targeting. This multifunctional protein is involved in the pathogenesis of many neurodegenerative diseases, including MS (45,56,57). It can influence protein-protein interactions, including those involving $\mathrm{NF}-\kappa \mathrm{B}$, which are known to play a critical role in the initiation and progression of MS $(58,59)$ and participate in the crosstalk with UPS at different levels of the NF- $\kappa \mathrm{B}$ signalling pathways (60). This splicing signal, affecting splicing and post-transcriptional modification of the majority of expressed genes in mammals, was shown to directly interact with PSMA3 proteins (61) and may be involved in the regulation of the PSMA3 gene expression through the rs 2348071 allele-specific targeting.

PSMA6-rs1048990 rare allele $\mathrm{G}$ generates binding sites for multifunctional p53 protein, overexpression of which can induce apoptosis of oligodendrocytes in MS (62). The PSMA6-rs2277460 substitution to A, produces binding sites for BARBIE box proteins, which are shown to be involved in innate immunity modulation (63). The major allele of PSMC6-rs2295826 generates sequence affinity to transcription 
A Controls

rs2348071 (AG+GG)

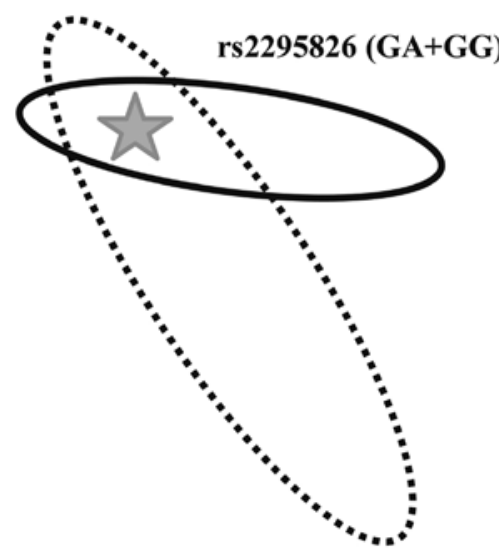

B $\quad \operatorname{rs2277460}(\mathrm{CA})$

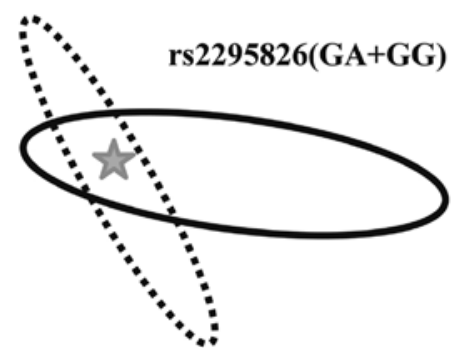

Multiple sclerosis rs2348071(AG+GG)

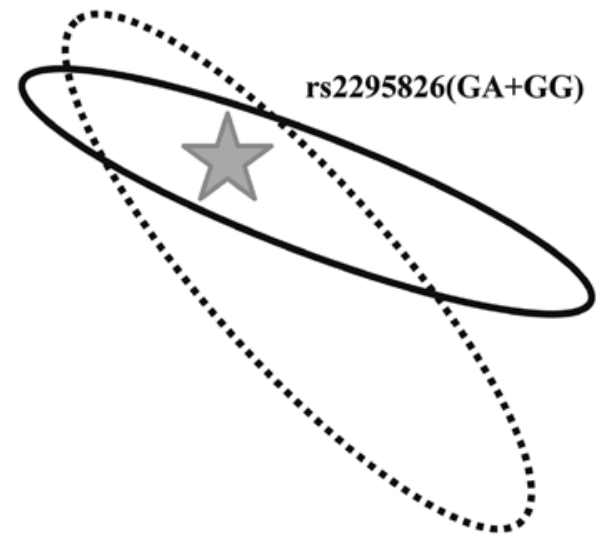

rs2277460 (CA)

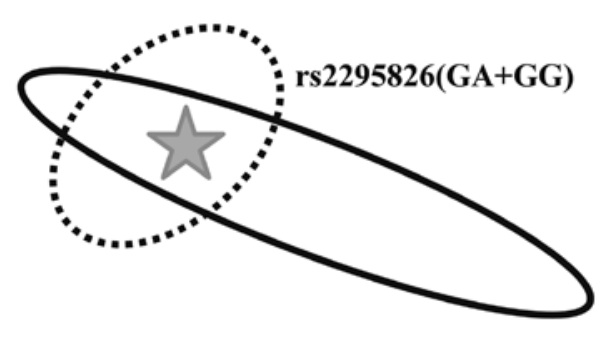

Figure 2. Visualization of the interaction between the components of multi-loci genotypes. (A) Interaction between the rs2295826-rs2295827 and rs2348071 MS risk genotypes. (B) Interaction between the rs2277460 rare CA genotype and MS risk genotypes at the rs2295826-rs2295827. Linkage block rs2295826-rs2295827 is represented by the rs2295826 locus. Two-loci genotypes associated with MS are localized in the cross of ellipses and marked by stars. The Square of the ellipses corresponds to the genotype frequency of the corresponding loci. MS, multiple scleroses.

factors of MYT1 and PARF families known to be involved in primary neurogenesis; substitution at the PSMC6-rs2295827 can bind the BRN5 and LHXF factors and replacement at the PSMA3-rs2348071 may significantly change patterns of the local targets for regulatory proteins of MEF2 and HBPX families known to mediate transcriptional control of neuronal differentiation (64-67); HOXF family NANOG.01 is involved in signal transduction pathways during development (68).

Previously, PSMA6-rs1048990 had shown to affect PSMA6 gene expression in vivo (69) and in vitro (40). However, it should be taken into account that the data on the possibility of a particular genetic variant to have multiple transcription effects are limited.

To explain the above speculation it should be kept in mind also, that changes in the expression of different proteasome subunits in response to outer factors is not co-ordinated. For example, cocaine mainly upregulates PSMBI and PSMA5 subunits, decreases PSMA6 subunit, but does not affect PSMB2 and PSMB5 subunit expression (70). Similar 'chaotic' changes in proteasome gene expression can happen in pathogenesis of the diseases, including MS. General expression of the proteasomes is increased in MS and, decreased by the interferon therapy (25). At the first stage of this process, the expression of the PSMA6 gene could increase, which can further promote the formation of more proteasomes with a subsequent increase in their activity. The same might happen with immune proteasome expression. The composition of $\alpha$ subunits in 'conventional' and immune proteasomes is identical. Thus, higher accessibility of PSMA6 subunits can favour initial increase of the formation of 'conventional' proteasomes with the transformation to immune proteasomes.

Based on the present and previously published results (38), we propose a concept for correlations between genotypes involved in MS risk and the level of expression of MS gene candidates. We should keep in mind that the expression studies in silico using data obtained for the lymphoblastoid cell line is a standard approach used for the MS studies (16).

A group of well-known MS gene candidates (Tables IV and SII) is represented by genes encoding the lymphocyte function-associated antigen 3 (CD58), MHC antigens (HLA-A and $H L A-B)$, interleukin-7 receptor subunit $\alpha$ $(I L 7 R)$, signal transducer and activator of transcription $3 S T A T 3$, tumor necrosis factor receptor superfamily member 5 [TNFRSF5 (CD40)].

The gene group involved in IFN $\alpha / \beta$ signalling pathway (Tables IV and SII) includes: Genes encoding interferon- $\alpha$ inducible protein 6 and interferon- $\alpha 1$ (IFI6 (G1P3) and IFNAI $(I F N \alpha)$, respectively), representatives of interferon regulatory factors (IRF1 and IRF2), proteins related to enzyme binding and protein domain specific binding (PRMT1 (HMRT1L2), PTP-1B (PTPN1), SHP-2 (PTPN11, TYK2 and USP18)). 
Table III. The rs 1048990 alleles and genotypes presentation in responders and non-responders to IFN $\beta$ therapy.

\begin{tabular}{|c|c|c|c|c|c|}
\hline \multirow[b]{2}{*}{ Allele or genotype } & \multicolumn{2}{|c|}{ IFN- $\beta$ (n) } & \multicolumn{3}{|c|}{ Statistics } \\
\hline & $\mathrm{R}$ & NR & Model & P-value & OR [95\% CI] \\
\hline $\mathrm{C}$ & $70(94.59)$ & 194 (87.39) & G vs. C & 0.059 & $2.53[0.90-7.08]$ \\
\hline G & $4(5.41)$ & $28(12.61)$ & G vs. CC & 0.056 & $2.69[0.92-7.84]$ \\
\hline $\mathrm{CC}$ & $33(89.19)$ & $86(77.48)$ & - & - & - \\
\hline CG & $4(10.81)$ & $22(19.82)$ & $\mathrm{CG}+\mathrm{GG}$ vs. $\mathrm{CC}$ & 0.090 & $2.40[0.78-7.42]$ \\
\hline GG & - & $3(2.70)$ & - & - & - \\
\hline
\end{tabular}

The numbers of alleles and genotypes (in brackets, frequency in percent) in the groups of study participants are presented as $\mathrm{n}(\%)$. $\mathrm{R}$, responders; NR, non-responders; IFN- $\beta$, interferon $\beta$; OR, odds ratio; CI, confidence interval.

Table IV. Data on correlation between mRNA expression and the rs1048990, rs2295826-rs2295827 and rs2348071 genotypes.

\begin{tabular}{|c|c|c|c|c|}
\hline Gene group & In correlation & Without correlation & $\begin{array}{l}\text { Not found on the } \\
\text { expression chip }\end{array}$ & Total \\
\hline MS & $\begin{array}{c}C D 58^{\mathrm{a}, \mathrm{d}}, H L A-A^{\mathrm{a}}, H L A-B^{\mathrm{b}, \mathrm{c}}, I L 7 R^{\mathrm{a}, \mathrm{d}}, S T A T 3^{\mathrm{a}, \mathrm{d}} \\
T N F R S F(C D 40)^{\mathrm{a}, \mathrm{d}}\end{array}$ & $\begin{array}{c}C D 6, H L A-D R B 1, I L 2 R A, I L 12 A, \\
I R F 8(I C S B P) \\
\text { TNFRSF } 1 A\end{array}$ & $C D 25$ & 13 \\
\hline IFN & $\begin{array}{c}I F I 6(G 1 P 3)^{\mathrm{d}}, I F N A 1(I F N \alpha)^{\mathrm{a}}, I R F 1^{\mathrm{a}}, I R F 2^{\mathrm{d}}, \\
P R M T 1(H M R T 1 L 2)^{\mathrm{d}}, P T P-1 B(P T P N 1)^{\mathrm{a}, \mathrm{d}} \\
\quad S H P-2(P T P N 11)^{\mathrm{d}}, T Y K 2^{\mathrm{a}}, U S P 18^{\mathrm{a}, \mathrm{d}}\end{array}$ & $\begin{array}{c}\text { IFNAR1, IFNAR2, IFNB1, ISG15 } \\
\text { (G1P2), ISG54 (IFIT2), ISGF3 } \\
(\text { IRF9), JAK1, PML (MYL), } \\
\text { SHP-1 (PTPN6), SOCS1, } \\
\text { STAT1, STAT2 }\end{array}$ & - & 21 \\
\hline
\end{tabular}

Total

MS, genes implicated in pathogenesis of multiple sclerosis (15-20); IFN, genes involved in IFN $\alpha / \beta$ signalling pathway (PathCards, https://pathcards.genecards.org/card/immune_response_ifn_alphabeta_signaling_pathway). ${ }^{a}$ rs $1048990, \quad{ }^{b}$ rs $2295826, \quad{ }^{c}$ rs 2295827 and ${ }^{\mathrm{d}} \mathrm{rs} 2348071$.

So, the expression of MS susceptible genes coding proteins of immune function (CD58, IL7R, STAT3, TNFRSF5 (CD40)) and genes involved in the IFN pathway (PTP-1B (PTPN1) and USP18) was found to be in a statistically significant correlation with the rs1048990 and rs2348071 risk genotypes simultaneously (Fig. 3B-F). Besides, among genes involved in IFN $\alpha / \beta$ signalling pathway the expression levels of IFI6 (GIP3), IRF2, PRMT1 (HMRT1L2) and SHP-2 (PTPN11) were found to be in a correlation only with PSMA3-rs2348071, but IFNA1 (IFN- $\alpha$ ), IRF1 and TYK2 genes correlate only with the PSMA6-rs1048990 (Table IV). Loci PCMC6-rs2295826 and rs2295827, were identified as susceptible to MS cohort in this study, are in a correlation with HLA-B encoding the MHC antigen expression level (Fig. 3A).

These results prove that the possibility of the combined functional effect of genetic risk factors on various metabolic aspects of MS pathogenesis is parallel with the potential for each SNP to have its own transcriptional effect on the genes involved in this study.

UPS components possess the potential of being a therapeutic target for the treatment of several diseases (71). IFN $\beta$ is a pleiotropic cytokine belonging to the type I interferons; it is involved in the regulation of innate and adaptive immune responses and is widely used as the first-line disease-modifying treatment for multiple sclerosis (72). Interestingly, among the studied loci, the association of the G allele at the PSMA6-rs1048990 with no IFN $\beta$ therapy response in the Latvian population in the current study was found to be close to statistical significance (Table III). It might be that with the increase in the number of patients in the studied cohorts, the significance of statistical reliability in this associative study can increase. The above data provided evidence of the cumulative effect of immune-response genes on IFN $\beta$ treatment efficacy.

The PSMA6-rs1048990-rs2277460, PSMC6-rs2295826rs2295827 and PSMA3-rs2348071 single- and multi-loci variations may contribute to the risk of MS in Latvians. The nucleotide substitutions may either have their own functional effect on transcription of numerous genes involved in MS pathogenesis or may be linked to other MS-susceptible genetic variations.

Our results suggested the potential for the rs1048990 of the PSMA6 gene to be an independent marker for the prognosis of the IFN $\beta$ therapy response. 

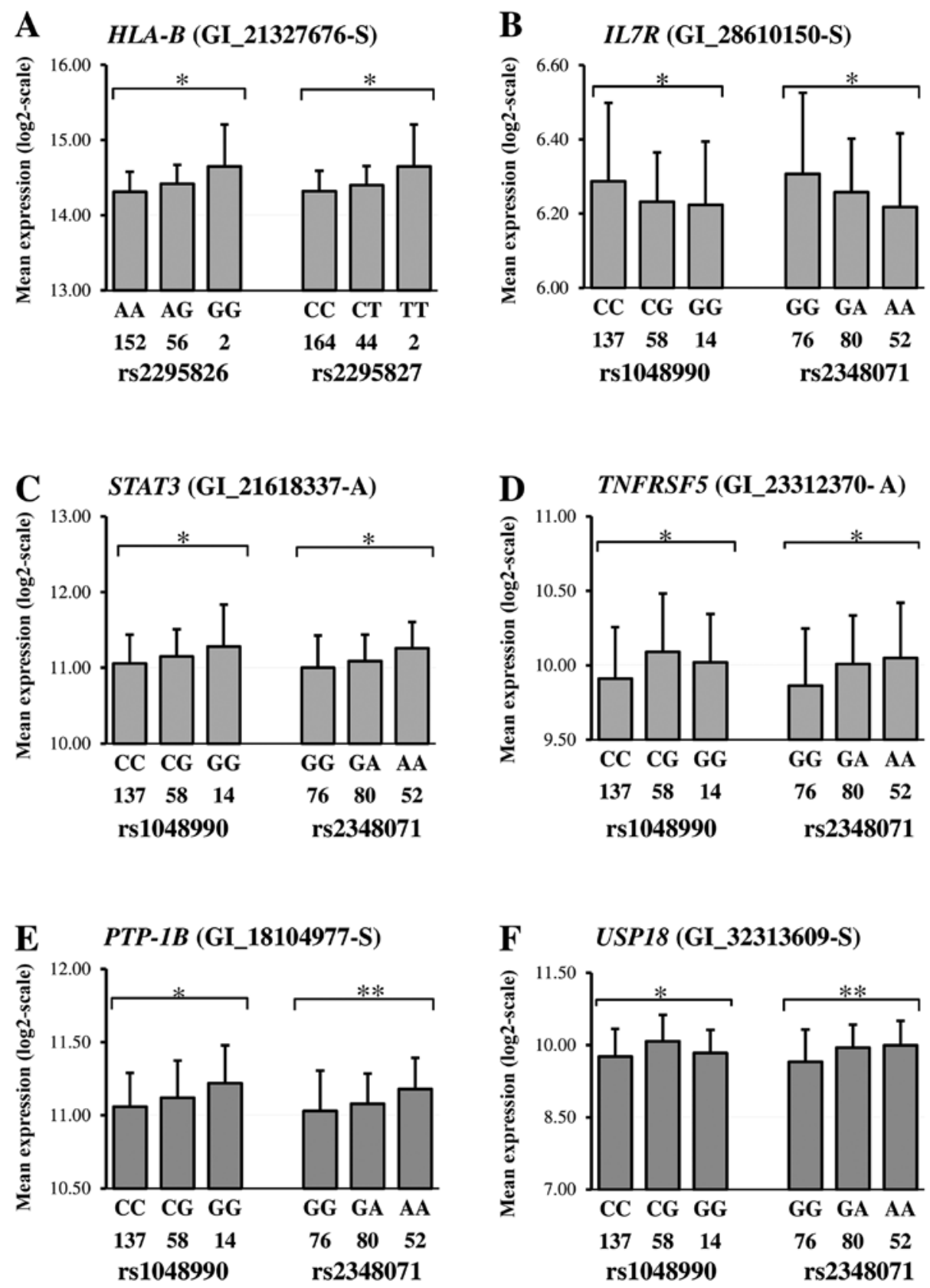

Figure 3. Gene expression according to genotypes. Genotyping data (number under genotype) and mRNA expression levels of the (A) $H L A-B$, (B) $I L 7 R$, (C) STAT3, (D) TBFRSF5, (E) PTP-1B and (F) USP18 were obtained from the HapMap phase II release 23 data set for lymphoblastoid cells of all unrelated individuals using publicly available SNPexp online tool (43). Each gene symbol is followed by the probe name indicated in brackets. Information on SNP genotypes and their quantitative presentation is given in the legends for the horizontal axis. Differences in mRNA expression between genotypes are given according to the dominant model and symbols. " $\mathrm{P}<0.05$ and ${ }^{* *} \mathrm{P}<0.001$. SNP, single nucleotide polymorphisms; PTP-1B, Protein tyrosine phosphatase $1 \mathrm{~B}$; USP18, Ubiquitin specific peptidase 18.

\section{Acknowledgements}

The authors would like to thank Ms Natalija Mjagkova (Latvian Maritime Medicine Centre, Riga, Latvia) for technical assistance.

\section{Funding}

The current study was funded by the European Regional Development Fund (project no. 1.1.1.1/16/A/016; 'Identification of proteasome related genetic, epigenetic and clinical markers for multiple sclerosis.').

\section{Availability of data and materials}

The datasets used and/or analysed during the current study are available from the corresponding author on reasonable request.

\section{Authors' contributions}

TS conceived of the study and acquired the funding. KDo and KDi analyzed and interpreted the data. IT performed the formal analysis. NP, KDo and KDi performed the experiments. IT and TS conceived of the methodology. NS and NP obtained resources and were associated with the project administration. 
KDo and KDi ran the software. JK performed data validation. NP, JK and NS confirmed the authenticity of all the raw data. NP and TS wrote the original draft of the manuscript. NP, KD, IT and NS wrote, reviewed and edited the manuscript. All authors read and approved the final manuscript.

\section{Ethics approval and consent to participate}

The present study was performed according to the Declaration of Helsinki and the study protocol was approved by the Central Medical Ethics Committee of Latvia (protocol no. 01-29.1/17). Informed consent was obtained from all individual participants included in the study.

\section{Patient consent for publication}

Not applicable.

\section{Competing interests}

The authors declare that they have no competing interests.

\section{References}

1. Compston A and Confavreux C: The distribution of multiple sclerosis. In: McAlPine's multiPle Sclerosis. 4th edition. Pioli S (ed). Churchill Livingstone/Elsevier, Philadelphia, pp69-180, 2006.

2. Bellavista E, Santoro A, Galimberti D, Comi C, Luciani F and Mishto M: Current understanding on the role of standard and immunoproteasomes in inflammatory/immunological pathways of multiple sclerosis. Autoimmune Dis 2014: 739705, 2014.

3. Miller AE: Multiple sclerosis: Where will we be in 2020? Mt Sinai J Med 78: 268-279, 2011.

4. Noseworthy JH,Lucchinetti C, Rodriguez M and Weinshenker BG: Multiple sclerosis. N Engl J Med 343: 938-952, 2000.

5. Song GG, Choi SJ, Ji JD and Lee YH: Genome-wide pathway analysis of a genome-wide association study on multiple sclerosis. Mol Biol Rep 40: 2557-2564, 2013.

6. Nicoletti F,Patti F, Cocuzza C,Zaccone P, Nicoletti A, Di Marco R and Reggio A: Elevated serum levels of interleukin-12 in chronic progressive multiple sclerosis. J Neuroimmunol 70: 87-90, 1996.

7. Nicoletti F, Di Marco R, Mangano K, Patti F, Reggio E, Nicoletti A Bendtzen K and Reggio A: Increased serum levels of interleukin-18 in patients with multiple sclerosis. Neurology 57: 342-244, 2001.

8. Cavalli E, Mazzon E, Basile MS, Mangano K, Di Marco R, Bramanti P, Nicoletti F, Fagone P and Petralia MC: Upregulated expression of macrophage migration inhibitory factor, its analogue D-dopachrome tautomerase, and the CD44 receptor in peripheral CD4 T cells from clinically isolated syndrome patients with rapid conversion to clinical defined multiple sclerosis. Medicina (Kaunas) 55: 667, 2019.

9. Fagone P, Mazzon E, Cavalli E, Bramanti A, Petralia MC, Mangano K, Al-Abed Y, Bramati P and Nicoletti F: Contribution of the macrophage migration inhibitory factor superfamily of cytokines in the pathogenesis of preclinical and human multiple sclerosis: In silico and in vivo evidences. J Neuroimmunol 322: 46-56, 2018.

10. Govindarajan V, de Rivero Vaccari JP and Keane RW: Role of inflammasomes in multiple sclerosis and their potential as therapeutic targets. J Neuroinflammation 17: 260, 2020.

11. Cavalli E, Mazzon E, Basile MS, Mammana S, Pennisi M, Fagone P, Kalfin R, Martinovic V, Ivanovic J Andabaka M, et al: In silico and in vivo analysis of IL37 in multiple sclerosis reveals its probable homeostatic role on the clinical activity, disability, and treatment with fingolimod. Molecules 25: 20, 2019.

12. Nicoletti F, Patti F, DiMarco R, Zaccone P, Nicoletti A, Meroni P and Reggio A: Circulating serum levels of IL-1ra in patients with relapsing remitting multiple sclerosis are normal during remission phases but significantly increased either during exacerbations or in response to IFN-beta treatment. Cytokine 8: 395-400, 1996.

13. Dujmovic I, Mangano K, Pekmezovic T, Quattrocchi C, Mesaros S, Stojsavljevic N, Nicoletti F and Drulovic J: The analysis of IL-1 beta and its naturally occurring inhibitors in multiple sclerosis: The elevation of IL-1 receptor antagonist and IL-1 receptor type II after steroid therapy. J Neuroimmunol 207: 101-106, 2009.
14. Fagone P, Patti F, Mangano K, Mammana S, Coco M, Touil-Boukoffa C, Chikovani T, Di Marco R and Nicoletti F: Heme oxygenase-1 expression in peripheral blood mononuclear cells correlates with disease activity in multiple sclerosis J Neuroimmunol 261: 82-86, 2013.

15. Australia and New Zealand Multiple Sclerosis Genetics Consortium (ANZgene) Genome-wide association study identifies new multiple sclerosis susceptibility loci on chromosomes 12 and 20. Nat Genet 41: 824-828, 2009.

16. International Multiple Sclerosis Genetics Conssortium (IMSGC): IL12A, MPHOSPH9/CDK2AP1 and RGS1 are novel multiple sclerosis susceptibility loci. Genes Immun 11: 397-405, 2010.

17. International Multiple Sclerosis Genetics Consortium, Hafler DA, Compston A, Sawcer S, Lander ES, Daly MJ, de Jager PL, de Bakker PI, Gabriel SB, Mirel DB, et al: Risk allels for multiple sclerosis identified by a genome wide study. N Engl J Med 357: 851-862, 2007.

18. De Jager PL, Jia X, Wang J, de Bakker PI, Ottoboni L, Aggarwal NT, Piccio L, Raychaudhuri S, Tran D, Aubin C, et al: Meta-analysis of genome scans and replication identify CD6, IRF8 and TNFRSF1A as new multiple sclerosis susceptibility loci. Nat Genet 41: 776-782, 2009.

19. Kofler DM, Severson CA, Mousissian N, De Jager PL and Hafler DA: The CD6 multiple sclerosis susceptibility allele is associated with alterations in $\mathrm{CD}^{+} \mathrm{T}$ cell proliferation. J Immunol 187: 3286-3291, 2011.

20. International Multiple Sclerosis Genetics Consortium; Wellcome Trust Case Control Consortium 2, Sawcer S, Hellenthal G, Pirinen M, Spencer CC, Patsopoulos NA, Moutsianas L, Dilthey A, Su Z, et al: Genetic risk and a primary role for cell-mediated immune mechanisms in multiple sclerosis. Nature 476: 214-219, 2011.

21. Zhang K, Chang S, Cui S, Guo L, Zhang L and Wang J: ICSNPathway: Identify candidate causal SNPs and pathways from genome-wide association study by one analytical framework. Nucleic Acids Res 39: W437-W443, 2011.

22. Fissolo N, Kraus M, Reich M, Ayturan M, Overkleeft H, Driessen $\mathrm{C}$ and Weissert R: Dual inhibition of proteasomal and lysosomal proteolysis ameliorates autoimmune central nervous system inflammation. Eur J Immunol 38: 2401-2411, 2008.

23. Mayo I, Arribas J, Villoslada P, Alvarez DoForno R, Rodríguez-Vilariño S, Montalban X, De Sagarra MR and Castaño JG: The proteasome is a major autoantigen in multiple sclerosis. Brain 125: 2658-2667, 2002.

24. Zheng J and Bizzozero OA: Decreased activity of the 20 S proteasome in the brain white matter and gray matter of patients with multiple sclerosis. J Neurochem 117: 143-153, 2011.

25. Minagar A, Ma W, Zhang X, Wang X, Zhang K, Alexander JS, Gonzalez-Toledo E and Albitar M: Plasma ubiquitin-proteasome system profile in patients with multiple sclerosis: Correlation with clinical features, neuroimaging, and treatment with interferon-beta-1b. Neurol Res 34: 611-618, 2012.

26. Pardo G and Jones DE: The sequence of disease-modifying therapies in relapsing multiple sclerosis: Safety and immunologic considerations. J Neurol 264: 2351-2374, 2017.

27. Nicoletti F, Di Marco R, Patti F, Reggio E, Nicoletti A, Zaccone P, Stivala F, Meroni PL and Reggio A: Blood levels of transforming growth factor-beta 1 (TGF-beta1) are elevated in both relapsing remitting and chronic progressive multiple sclerosis (MS) patients and are further augmented by treatment with interferon-beta $1 \mathrm{~b}$ (IFN-beta1b). Clin Exp Immunol 113: 96-99, 1998.

28. Patti F, Cataldi ML, Nicoletti F, Reggio E, Nicoletti A and Reggio A: Combination of cyclophosphamide and interferon-beta halts progression in patients with rapidly transitional multiple sclerosis. J Neurol Neurosurg Psychiatry 71: 404-407, 2001.

29. Fagone P, Mazzon E, Mammana S, Di Marco R, Spinasanta F, Basile MS, Petralia MC, Bramanti P, Nicoletti F and Mangano K: Identification of $\mathrm{CD}^{+} \mathrm{T}$ cell biomarkers for predicting the response of patients with relapsing-remitting multiple sclerosis to natalizumab treatment. Mol Med Rep 20: 678-684, 2019.

30. Derfuss T, Mehling M, Papadopoulou A, Bar-Or A, Cohen JA and Kappos L: Advances in oral immunomodulating therapies in relapsing multiple sclerosis. Lancet Neurol 19: 336-347, 2020.

31. Kulakova OG, Tsareva EY, Boyko AN, Shchur SG, Gusev EI, Lvovs D, Favorov AV, Vandenbroeck K and Favorova OO: Allelic combinations of immune-response genes as possible composite markers of IFN- $\beta$ efficacy in multiple sclerosis patients. Pharmacogenomics 13: 1689-1700, 2012.

32. Kalnina J, Paramonova N, Sjakste N and Sjakste T: Study of association between polymorphisms in the PSMB5 (rs11543947) and PSMA3 (rs2348071) genes and multiple sclerosis in Latvians. Biopolymers Cell 30: 305-309, 2014. 
33. Mishto M, Bellavista E, Ligorio C, Textoris-Taube K, Santoro A, Giordano M, D'Alfonso S, Listì F, Nacmias B, Cellini E, et al: Immunoproteasome LMP2 $60 \mathrm{HH}$ variant alters MBP epitope generation and reduces the risk to develop multiple sclerosis in Italian female population. PLoS One 5: e9287, 2010.

34. Sjakste T, Paramonova N, Rumba-Rozenfelde I, Trapina I, Sugoka O and Sjakste N: Juvenile idiopathic arthritis subtype- and sex-specific associations with genetic variants in the PSMA6/PSMC6/PSMA3 gene cluster. Pediatr Neonatol 55: 393-403, 2014.

35. Paramonova N, Wu LS, Rumba-Rozenfelde I, Wang JY, Sjakste $\mathrm{N}$ and Sjakste T: Genetic variants in the PSMA6, PSMC6 and PSMA3 genes associated with childhood asthma in Latvian and Taiwanese populations. Biopolymers Cell 30: 377-387, 2014

36. Paramonova N, Kupca S, Rumba-Rozenfelde I, Sjakste N and Sjakste T: Association between the PSMB5 and PSMC6 genetic variations and children obesity in the Latvian population. Biopolymers Cell 30: 477-480, 2014.

37. Sjakste T, Kalis M, Poudziunas I, Pirags V, Lazdins M, Groop L and Sjakste N: Association of microsatellite polymorphisms of the human 14q13.2 region with type 2 diabetes mellitus in Latvian and Finnish populations. Ann Hum Genet 71: 772-776, 2007.

38. Sjakste T, Paramonova N, Osina K, Dokane K, Sokolovska J and Sjakste N: Genetic variations in the PSMA3, PSMA6 and PSMC6 genes are associated with type 1 diabetes in Latvians and with expression level of number of UPS-related and T1DM-susceptible genes in HapMap individuals. Mol Genet Genomics 291: 891-903, 2016.

39. Sjakste T, Poudziunas I, Ninio E, Perret C, Pirags V, Nicaud V, Lazdins M, Evanss A, Morrison C, Cambien F and Sjakste N: SNPs of PSMA6 gene-investigation of possible association with myocardial infarction and type 2 diabetes mellitus. Genetika 43: 553-559, 2007.

40. Wang H, Jiang M, Zhu H, Chen Q, Gong P, Lin J, Lu J and Qiu J: Quantitative assessment of the influence of PSMA6 variant (rs1048990) on coronary artery disease risk. Mol Biol Rep 40: 1035-1041, 2013

41. Sjakste T, Paramonova N, Wu LS, Zemeckiene Z, Sitkauskiene B, Sakalauskas R, Wang JY and Sjakste N: PSMA6 (rs2277460, rs1048990), PSMC6 (rs2295826, rs2295827) and PSMA3 (rs2348071) genetic diversity in Latvians, lithuanians and taiwanese. Meta Gene 2: 283-298, 2014

42. Rojas-Villarraga A, Amaya-Amaya J, Rodriguez-Rodriguez A, Mantilla RD and Anaya JM: Introducing polyautoimmunity: Secondary autoimmune diseases no longer exist. Autoimmune Dis 2012: 254319, 2012

43. Holm K, Melum E, Franke A and Karlsen TH: SNPexp-A web tool for calculating and visualizing correlation between HapMap genotypes and gene expression levels. BMC Bioinformatics 11: $600,2010$.

44. Polman CH, Reingold SC, Banwell B, Clanet M, Cohen JA, Filippi M, Fujihara K, Havrdova E, Hutchinson M, Kappos L, et al: Diagnostic criteria for multiple sclerosis: 2010 Revisions to the McDonald criteria. Ann Neurol 69: 292-302, 2011

45. Stangel M, Penner IK, Kallmann BA, Lukas C and Kieseier BC: Towards the implementation of 'no evidence of disease activity' in multiple sclerosis treatment: The multiple sclerosis decision model. Ther Adv Neurol Disord 8: 3-13, 2015.

46. Lewis CM: Genetic association studies: Design, analysis and interpretation. Brief Bioinform 3: 146-153, 2002

47. Alsmadi O, Muiya $\mathrm{P}$, Khalak H, Al-Saud H, Meyer BF, Al-Mohanna F, Alshahid M and Dzimiri N: Haplotypes encompassing the KIAA0391 and PSMA6 gene cluster confer a genetic link for myocardial infarction and coronary artery disease. Ann Hum Genet 73: 475-483, 2009.

48. Andreassen OA, Harbo HF, Wang Y, Thompson WK, Schork AJ, Mattingsdal M, Zuber V, Bettella F, Ripke S, Kelsoe JR, et al: Genetic pleiotropy between multiple sclerosis and schizophrenia but not bipolar disorder: Differential involvement of immune-related gene loci. Mol Psychiatry 20: 207-214, 2015.

49. Lee S, Xu L, Shin Y, Gardner L, Hartzes A, Dohan FC, Raine C, Homayouni R and Levin MC: A potential link between autoimmunity and neurodegeneration in immune-mediated neurological disease. J Neuroimmunol 235: 56-69, 2011.

50. Thompson SD, Barnes MG, Griffin TA, Grom AA and Glass DN: Heterogeneity in juvenile idiopathic arthritis: Impact of molecular profiling based on DNA polymorphism and gene expression patterns. Arthritis Rheum 62: 2611-2615, 2010.

51. Sivakumaran S, Agakov F, Theodoratou E, Prendergast JG, Zgaga L, Manolio T, Rudan I, McKeigue P, Wilson JF and Campbell H: Abundant pleiotropy in human complex diseases and traits. Am J Hum Genet 89: 607-618, 2011.
52. Hallstrand TS, Fischer ME, Wurfel MM, Afari N, Buchwald D and Goldberg J: Genetic pleiotropy between asthma and obesity in a community-based sample of twins. J Allergy Clin Immunol 116: 1235-1241, 2005.

53. Murphy A, Tantisira KG, Soto-Quirós ME, Avila L, Klanderman BJ, Lake S, Weiss ST and Celedón JC: PRKCA: A positional candidate gene for body mass index and asthma. Am J Hum Genet 85: 87-96, 2009.

54. Lee SH, Lee EB, Shin ES, Lee JE, Cho SH, Min KU and Park HW: The interaction between allelic variants of CD86 and CD40LG: A common risk factor of allergic asthma and rheumatoid arthritis. Allergy Asthma Immunol Res 6: 137-141, 2014.

55. Ramírez-Bello J, Jiménez-Morales S, Espinosa-Rosales F, Gómez-Vera J, Gutiérrez A, Velázquez Cruz R, Baca V and Orozco L: Juvenile rheumatoid arthritis and asthma, but not childhood-onset systemic lupus erythematosus are associated with FCRL3 polymorphisms in Mexicans. Mol Immunol 53: 374-378, 2013.

56. Johnson DA, Amirahmadi S, Ward C, Fabry Z and Johnson JA The absence of the pro-antioxidant transcription factor Nrf2 exacerbates experimental autoimmune encephalomyelitis. Toxicol Sci 114: 237-246, 2010.

57. Bekenstein U and Soreq H: Heterogeneous nuclear ribonucleoprotein A1 in health and neurodegenerative disease: From structural insights to post-transcriptional regulatory roles. Mol Cell Neurosci 56: 436-446, 2013.

58. Leibowitz SM and Yan J: NF- $\mathrm{BB}$ pathways in the pathogenesis of multiple sclerosis and the therapeutic implications. Front Mol Neurosci 9: 84, 2016.

59. Yue Y, Stone S and Lin W: Role of nuclear factor $\kappa B$ in multiple sclerosis and experimental autoimmune encephalomyelitis. Neural Regen Res 13: 1507-1515, 2018.

60. Wu ZH and Shi Y: When ubiquitin meets NF- $\mathrm{BB}$ : A trove for anti-cancer drug development. Curr Pharm Des 19: 3263-3275, 2013.

61. Fedorova OA, Moiseeva TN, Nikiforov AA, Tsimokha AS, Livinskaya VA, Hodson M, Bottrill A, Evteeva IN, Ermolayeva JB, Kuznetzova IM, et al: Proteomic analysis of the 20S proteasome (PSMA3)-interacting proteins reveals a functional link between the proteasome and mRNA metabolism. Biochem Biophys Res Commun 416: 258-265, 2011.

62. Wosik K, Antel J, Kuhlmann T, Brück W, Massie B and Nalbantoglu J: Oligodendrocyte injury in multiple sclerosis: A role for p53. J Neurochem 85: 635-644, 2003.

63. Dozmorov M, Wu W, Chakrabarty K, Booth JL, Hurst RE, Coggeshall KM and Metcalf JP: Gene expression profiling of human alveolar macrophages infected by B. anthracis spores demonstrates TNF-alpha and NF-kappab are key components of the innate immune response to the pathogen. BMC Infect Dis 9: 152, 2009

64. Gill GN: Decoding the LIM development code. Trans Am Clin Climatol Assoc 114: 179-189, 2003.

65. Phillips K and Luisi B: The virtuoso of versatility: POU proteins that flex to fit. J Mol Biol 302: 1023-1039, 2000.

66. She $\mathrm{H}$ and Mao Z: Regulation of myocyte enhancer factor-2 transcription factors by neurotoxins. Neurotoxicology 32: 563-566, 2011.

67. Uzumcu A, Karaman B, Toksoy G, Uyguner ZO, Candan S, Eris H, Tatli B, Geckinli B, Yuksel A, Kayserili H and Basaran S: Molecular genetic screening of MBS1 locus on chromosome 13 for microdeletions and exclusion of FGF9, GSH1 and CDX2 as causative genes in patients with Moebius syndrome. Eur J Med Genet 52: 315-320, 2009.

68. Ho B, Olson G, Figel S, Gelman I, Cance WG and Golubovskaya VM: Nanog increases focal adhesion kinase (FAK) promoter activity and expression and directly binds to FAK protein to be phosphorylated. J Biol Chem 287: 18656-18673, 2012.

69. Ozaki K, Sato H, Iida A, Mizuno H, Nakamura T, Miyamoto Y, Takahashi A, Tsunoda T, Ikegawa S, Kamatani N, et al: A functional SNP in PSMA6 confers risk of myocardial infarction in the Japanese population. Nat Genet 38: 921-925, 2006.

70. Caputi FF, Carboni L, Mazza D, Candeletti S and Romualdi P. Cocaine and ethanol target 26S proteasome activity and gene expression in neuroblastoma cells. Drug Alcohol Depend 161: 265-275, 2016

71. Bedford L, Lowe J, Dick LR, Mayer RJ and Brownell JE: Ubiquitin-like protein conjugation and the ubiquitin-proteasome system as drug targets. Nat Rev Drug Discov 10: 29-46, 2011.

72. Torkildsen $\varnothing$, Myhr KM and B $\varnothing$ L: Disease-modifying treatments for multiple sclerosis-a review of approved medications Eur J Neurol 23 (Suppl 1): S18-S27, 2016.

This work is licensed under a Creative Commons Attribution-NonCommercial-NoDerivatives 4.0 International (CC BY-NC-ND 4.0) License. 